\title{
Sexual excitation function of hamster vaginal secretion
}

\author{
ROBERT E. JOHNSTON \\ Cornell University, Ithaca, New York 14850
}

\begin{abstract}
Sexually naive male hamsters were paired with ovariectomized females or with castrated males. On half of the trial days, the stimulus animals were scented with vaginal secretion from estrous females, and on half of the trials they were left unscented. Added vaginal secretion resulted in an increased frequency of mounting and decreased latency to mount, and an increase in the amount of time the males remained near the stimulus animals. These results demonstrate that the vaginal secretion has attractant and sexual excitant effects on naive males and thus is a source of sex pheromones. Presence of the secretion also resulted in a decrease in some measures of agonistic behavior, suggesting anti-aggressive functions as well.
\end{abstract}

An increasing body of literature documents the importance of olfaction in communication among mammals, and especially in the coordination and control of sexual behavior and reproductive function (Bronson, 1968; Eisenberg \& Kleiman, 1972; Ewer, 1968; Johnson, 1973; Michael, Keverne, \& Bonsall, 1971; Mykytowycz, 1970; Ralls, 1971; Schultz \& Tapp, 1973; Whitten, 1966). Male hamsters lacking olfactory bulbs or with peripheral olfactory blockage do not mate with receptive females, indicating the importance of a functional olfactory system for at least the initiation of sexual behavior (Devor \& Murphy, 1972, 1973; Lisk, Zeiss \& Ciaccio, 1972; Murphy \& Schneider, 1970). Such deficits could be due to lack of rhythmic input to the central nervous system from the olfactory bulb or to lack of olfactory information per se, or both. Investigations of the functions of the hamster vaginal secretion indicate that the lack of olfactory information is certainly involved.

The hamster vaginal secretion changes regularly in volume and consistency with the estrous cycle (Orsini, 1961) and the maximum production of the secretion, which occurs just prior to and during estrus, is hormone dependent (Brom \& Schwartz, 1968). A stereotyped scent marking behavior serves to deposit this secretion (Dieterlen, 1959) and the frequency of vaginal marking correlates with estrous cycle, reaching a peak the day before estrus (Johnston, 1970, Note 1, Note 2, and Note 3). The male hamster sniffs and licks the female's genital region prior to copulation and the female extrudes the vaginal secretion which is then licked and consumed by the male (Johnston, 1970; Murphy \& Schneider, 1970). These observations all suggest sex pheromone functions for the vaginal secretion, and recent reports have experimentally demonstrated some of these functions. First, males are highly attracted to the secretion, and will spend a large proportion of test

This research was supported by an award to the author from the Cornell University Research Grants Committee and by a National Science Foundation Institutional Grant GU-3546 to Cornell University. I am grateful to Bill Esson for technical comments on the manuscript. Requests for reprints should be sent to Robert E. Johnston, Dept. of Psy chology, Cornell University, Ithaca, New York 14850. time sniffing its odor (Devor \& Murphy, 1972; Johnston, 1970, 1972, 1974d; Murphy, 1973). Second, the secretion has sexual excitatory effects: its presence is sufficient to elicit mating attempts toward inappropriate hamster partners such as docile males or anesthetized males. Lisk, Zeiss and Ciaccio (1972) showed that sexually naive males would mount docile males anointed with vaginal secretion but presented few details of the males' behavior. Murphy (1973) presented much more behavioral detail but used sexually experienced males. The experiments presented here were designed to determine in greater detail the effects of the vaginal secretion on the behavior of sexually naive males. The experiments were carried out without knowledge of those cited above; an abstract has appeared previously (Johnston, 1972). A second purpose was to investigate the value of different stimulus animals for ultimate use in behavioral bioassays of the vaginal secretion.

\section{GENERAL METHODS}

All hamsters were caged individually in solid bottom cages $9 \times 15 \times 9$ in.; food and water were always available. They were maintained on a reversed day-night cycle of $12 \mathrm{~h}$ bright and $12 \mathrm{~h}$ dim illumination. The temperature was maintained at $70^{\circ} \pm 2^{\circ} \mathrm{F}$ and the relative humidity was $50 \%$. All animals, including castrated and ovariectomized stimulus animals, were obtained from Lakeview Hamster Colony, Newfield, New Jersey; test animals were 28-30 days old when received and were sexually naive before these experiments.

Testing took place in painted wooden boxes $2 \times 3 \times 1 \mathrm{ft} \mathrm{high}$; the front wall of the box was glass. These boxes were subdivided into six compartments with passageways between them. There were two doors that could be closed by the experimenter and, when closed, they created three separate areas $1 \times 2 \mathrm{ft}$ extending from the front to the back of the box-one on the left side, one down the center, and one on the right side. A mirror was mounted above the testing boxes at a 45 -deg angle so that the experimenter could follow the action throughout all compartments. There was a separate testing box for each pair of animals, and each individual of a pair was given three 10-min habituation trials alone in the box on the 3 days prior to testing. Tests, consisting of 5 -min encounter periods, were run $2-3 \mathrm{~h}$ after the beginning of the dim phase of the light cycle; they were carried out under dim illumination (one $40-\mathrm{W}$ bulb illuminated the testing room). Each individual of a pair was allowed to go from its home cage into one end of the testing box and the 
Table 1

Mean Times (in Seconds) or Frequency Per 5-Min Trial for Behavioral Categories in the Presence or Absence of Exogenous Vaginal Secretion

\begin{tabular}{lrrrr}
\hline & \multicolumn{3}{c}{$\begin{array}{c}\text { No Secre- } \\
\text { tion }\end{array}$} & $\begin{array}{c}\text { Significance of } \\
\text { Difference* }\end{array}$ \\
Behavioral Category & $\begin{array}{c}\text { Secretion } \\
\text { Added }\end{array}$ & $\begin{array}{c}\text { tdded } \\
\text { Add }\end{array}$ & & \\
\hline Sexual Behaviors & & & & \\
$\quad$ Mounting (Sec) & 27.5 & 6.0 & $<.02$ & 3.689 \\
$\quad$ Mounting Frequency & 7.4 & 1.9 & $<.02$ & 3.258 \\
$\quad$ Latency to Mount & 173.2 & 247.2 & $<.005$ & 4.389 \\
Agonistic Behaviors & & & & \\
Mutual Posturing & 21.9 & 25.3 & n.s. & 1.166 \\
Tumble & 10.0 & 7.0 & n.s. & 1.127 \\
Fight/Chase & 2.8 & .8 & n.s. & 1.978 \\
Flank Mark During & .8 & 1.7 & n.s. & 2.415 \\
$\quad$ Flank Mark After & 2.9 & 6.4 & $<.05$ & 2.717 \\
Other Behaviors & & & & \\
Sniff Genitals & 58.8 & 56.5 & n.s. & .573 \\
Sniff Head & 5.4 & 6.7 & n.s. & .565 \\
Sniff Other & 22.0 & 29.2 & n.s. & 2.365 \\
Time Within 1 Min & 244.8 & 224.8 & $<.05$ & 2.927 \\
Time 5 Min or More & 52.2 & 70.3 & $<.05$ & 2.586 \\
\hline
\end{tabular}

Note-Seven male-ovariectomized female pairs were obseried. Two-tailed $t$ test.

animals were kept separated for 1-2 min. The stimulus animal (ovariectomized female or castrated male) was picked up and the genital region was rubbed with a wooden Q-tip stick which was either clean (control condition) or was covered with freshly collected vaginal secretion (test condition). The stimulus animal was returned to its end of the box and allowed to remain there for approximately $30 \mathrm{sec}$ before the beginning of the 5 -min encounter. After the encounter period, the stimulus animal was removed, and the experimental male was observed for another $2 \mathrm{~min}$ in the testing box. On any given day, pairs that were tested without vaginal secretion were tested first.

Vaginal secretion was collected in the following manner from estrous females in a separate room just before each test. The estrous female was put into a $2 \times 2-\mathrm{ft}$ box and allowed approximately $1 \mathrm{~min}$ to explore; a male was briefly introduced until the female went into lordosis. The secretion was then collected on the bare end of a wooden Q-tip stick.

Behavioral categories were recorded on a 20-channel event recorder. During encounters, behaviors of the test males recorded were: sniffing genital region, sniffing head region, sniffing other regions, attempted mounting while stimulus animal moving, attempted mounting while animal still, change of compartment, grooming and flank marking. Behaviors of the stimulus animal recorded were flank marking and vaginal marking. Behaviors of both animals recorded were: mutual agonistic postures, tumble (interlocked rolling on floor), fight and/or chase (vigorous fight with quick, convulsive movements, clearly distinct from tumble), 1 in. or less between the two animals, and greater than 5 in. between the two animals. During the 2-min observation period following the encounter, the behaviors recorded were: flank marking, digging, climbing, gnawing, change of compartment, and grooming. Multiple two-tailed $t$ tests were used to compare the means for stimulus and control conditions.

Four experiments were run: in the first, ovariectomized females were the stimulus animals and in the three subsequent experiments, castrated males were used. Since in the third and fourth experiments few significant differences were obtained, these data are not presented in detail.

\section{EXPERIMENT I}

In this experiment, males were paired with ovariectomized females as stimulus animals. For comparison, two males were paired with normal females and tested when the females were not estrous and were, therefore, aggressive toward males (Johnston, 1970, 1974a; Payne \& Swanson, 1970).

\section{Methods}

Nine sexually naive males either 5 or 10 months old were used; seven were paired with ovariectomized females and two with normal females. Each pair was then tested once per day for 18 days; vaginal secretion was rubbed onto the genital region of stimulus females on 8 or 9 of the test days. The sequence of secretion and control days was irregular and differed for each pair.

\section{Results and Discussion}

Six of the seven males attempted to mount the ovariectomized females, and all of these six males attempted to mount more frequently when exogenous vaginal secretion was added than when no vaginal secretion was added. Mean mounting frequency for the entire group of seven males was 7.4 mounts per trial with secretion and 1.9 mounts per trial in the control condition (Table $1, t=3.258, \mathrm{df}=6, \mathrm{p}<.02$ ). Since the mean number of seconds per mount attempt was similar in the secretion condition $(3.6 \mathrm{sec})$ and the control condition $(3.2 \mathrm{sec})$, the greater time spent in mount attempts toward scented females shown in Table 1 was largely due to the increased frequency of mount attempts and not to an increased duration of each attempted mount. Mounting occurred during $49.2 \%$ of all trials in which vaginal secretion was added and during $28.8 \%$ of trials in which no secretion was added. On trials in which mounting did occur, the mean frequency was still greater when vaginal secretion was added (15.0 mounts per trial) than when it was not added (5.5 mounts per trial), an effect which was displayed by all six males that did mount $(\mathrm{t}=7.898, \mathrm{df}=5, \mathrm{p}<.001)$.

The latency to mount was much shorter in the presence of exogenous secretion, $173.2 \mathrm{sec}$, than in its absence, $247.2 \mathrm{sec}(t=4.389$, df $=6, p<.005)$. If the latency to mount is calculated only for those trials on which mounting did occur, all six males who did mount showed a shorter mean latency to mount with added vaginal secretion (group mean, $68.1 \mathrm{sec}$ ) than without (group mean, 118.1 sec). The presence of exogenous vaginal secretion on stimulus females also increased their attractiveness, as reflected by the two measures of proximity; males spent significantly more time within 1 in. of scented females and significantly less time 5 in. or more away from such females (Table 1).

There was much less mounting by males paired with normal females, primarily because these females were more aggressive than the ovariectomized females; both 
of the normal females were dominant over their male partners. Nonetheless, the addition of exogenous vaginal secretion increased the frequency of mount attempts from .4 to .9 per trial, increased the percentage of trials on which mount attempts occurred from $18 \%$ to $47 \%$, and decreased the mean latency to mount by $40 \mathrm{sec}$.

Thus vaginal secretion from estrous females caused an increase in sexual motivation in the experimental males. However, the presence or absence of the secretion did not wholly determine the behavior of the males, as shown by the fact that on half of the trials when secretion was present no mount attempts occurred. Furthermore, in only one pair did the first mount attempt occur on the first trial in which vaginal secretion was present. Very little mounting was observed in any pair during the first few trials, indicating that social experience in the experiment influenced the males' behavior considerably. On the other hand, five of the six males that did mount first did so during a trial when exogenous secretion was present, indicating the potency of the vaginal secretion in initiating sexual behavior.

There were no significant differences in overt agonistic behavior between secretion and no secretion trials (Table 1). However, flank marking after encounters was less frequent when exogenous vaginal secretion was added (Table 1, $\mathrm{p}<.05$ ) and during encounters there was a nonsignificant trend in the same direction $(p<.1)$. It has been previously demonstrated that flank marking frequency is positively correlated with agonistic arousal and negatively correlated with sexual motivation (Johnston, 1970, 1974a).

Males spent considerable time sniffing at the genital region of both artificially scented and control females, and there was no difference between the two conditions. This suggests that the ovariectomized females may have been producing vaginal secretion of their own. After this experiment was completed, a report by Darby, Devor, and Chorover (1974) demonstrated that males do sniff and lick secretion from ovariectomized females.

There were no significant differences in any other behavioral categories recorded during or after encounters.

\section{EXPERIMENT II}

The males in Experiment I did mount the unscented ovariectomized females, and they spent considerable time sniffing the genital region of such females. Qualitatively, it seemed that the males behaved as if the stimulus animals were females, and not as if they were sexually neutral. The effect of ovariectomy on production of the vaginal secretion is not known in detail. The presence of the ovary is necessary for the peak in production which occurs during estrus (Brom \& Schwartz, 1968), but ovariectomized females apparently continue to produce some vaginal secretion (Darby, Devor, \& Chorover, 1974). In addition, other olfactory or behavioral cues from the ovariectomized females could have affected the males' propensity to engage in sexual behavior. Therefore, a second experiment was run using castrated males as the stimulus animals to investigate the effects of the vaginal secretion in the absence of other cues from female hamsters.

\section{Methods}

The general procedures were the same as in Experiment I. Six sexually naive male hamsters, 11 months of age, served as the experimental animals. The castrated stimulus males were obtained from Lakeview Hamster Colony and were 2 months old when the experiment began. Pairs were tested on 18 consecutive days; the first 4 days for all pairs were "clean control" days and served as habituation trials. Seven of the last 14 trials were stimulus trials; the order of secretion and control trials was irregular and unique for each pair-thus between four and seven trials occurred before the first trial on which vaginal secretion was added. Since male hamsters generally show no sexual behavior towards castrated males, the initial encounters with unscented castrates should not change the "sexually naive" status of the experimental males (Payne \& Swanson, 1972; Johnston, unpublished observations). In contrast to Experiment I, the experimental males were not observed following the encounter period. Due to a malfunctioning event recorder pen, data in the "time within 1 in." category was not obtained throughout and is not included.

\section{Results}

Five of the six males showed considerably more sexual behavior towards castrated males when vaginal secretion was present than when it was absent, while the sixth male never engaged in any sexual behavior. Of the five sexually active males, four first attempted to mount on a vaginal secretion trial; three of these did so on the first vaginal secretion trial and one did so on the second secretion trial. Only one male consistently attempted to mount an unscented partner, and although his first mount attempts occurred during one of the habituation trials, he did not mount again on "clean" trials until Trial 12, after several exposures to vaginal secretion during which he did mount.

During test trials, the mean mounting frequency for each of the five sexually active males was $1.0,5.3,6.3$, 7.8 , and 8.3 mounts per trial with scented partners vs. $0.0,0.1,0.0,4.0$, and 2.7 mounts per trial, respectively, with unscented partners. The difference between mounting frequency with vaginal secretion and without vaginal secretion for the entire group of six males was significant at $\mathrm{p}<.02$ (Table $2, \mathrm{t}=3.449, \mathrm{df}=5$ ). The time engaged in mounting attempts was also much greater in the presence of vaginal secretion (mean, $15.7 \mathrm{sec}$ ) compared to its absence (mean, $3.0 \mathrm{sec}$; $t=2.580, p<.05$ ), and the latency to mount was considerably shorter with secretion $(180.7 \mathrm{sec})$ as opposed to without $(256.5 \mathrm{sec}, \mathrm{t}=2.688, \mathrm{p}<.05)$. Furthermore, in secretion trials mean mounting frequency and time in mount attempts were much greater, while mean latency to mount was much less, than in habituation trials (Table 2, all significant at $\mathrm{p}<.05$ or less). 
Table 2

Mean Times (in Seconds) or Frequency Per 5-Min Trial for Behavioral Categories During Habituation Trials and Test Trials

\begin{tabular}{|c|c|c|c|}
\hline \multirow[b]{2}{*}{ Behavioral Category } & \multirow[b]{2}{*}{$\begin{array}{c}\text { Habitu- } \\
\text { ation } \\
\text { Trials }\end{array}$} & \multicolumn{2}{|c|}{ Test Trials } \\
\hline & & $\begin{array}{l}\text { Secre- } \\
\text { tion } \\
\text { Added }\end{array}$ & $\begin{array}{c}\text { No Secre } \\
\text { tion } \\
\text { Added }\end{array}$ \\
\hline \multicolumn{4}{|l|}{ Sexual Behaviors } \\
\hline Mounting (Sec) & $.4 \dagger$ & $15.7^{*}$ & 3.0 \\
\hline Mounting Frequency & $.2 \dagger \dagger$ & $4.8 * *$ & 1.1 \\
\hline Latency to Mount & $294.1 \dagger \dagger$ & $180.7^{*}$ & 256.5 \\
\hline \multicolumn{4}{|l|}{ Agonistic Behaviors } \\
\hline Mutual Posturing & $63.7 \dagger \dagger \uparrow, 末$ & $21.8 * * *$ & 31.1 \\
\hline Tumble & 2.9 & 3.3 & 4.1 \\
\hline Fight/Chase & .4 & .5 & .5 \\
\hline Flank Mark Frequency & .7 & .4 & 2.7 \\
\hline \multicolumn{4}{|l|}{ Other Behaviors } \\
\hline Sniff Genitals & $30.8 \dagger+\dagger \dagger$ & $74.9^{*}$ & 41.2 \\
\hline Sniff Head & 10.4 & 8.6 & 11.7 \\
\hline Sniff Other & 17.2 & 27.3 & 32.3 \\
\hline Time $5 \mathrm{Sec}$ or More & 92.6 & $39.3 *$ & 78.1 \\
\hline
\end{tabular}

Note-Six male-castrated male pairs were tested. Two-tailed $t$ tests for all comparisons:

$t_{p}<.05,+\dagger .02,+\dagger+.01,+t+\dagger .005$ habituation $v$ s. secretion trials. ${ }^{*} p<.05,{ }^{* *} p<.02,{ }^{* * *} p<.01$ secretion vs. no secretion test trials.

$\ddagger p<.05$ habituation vs. no secretion test trials.

Whereas mounting occurred on only one habituation trial $(4.2 \%)$, it occurred on $64 \%$ of vaginal secretion trials and $16.7 \%$ of clean control trials. The difference between habituation and control trials is even larger if the percentages are recalculated on the basis of all trials (habituation trials plus test trials) which occurred before a male had been exposed to the vaginal secretion: mount attempts occurred during only one trial $(2.8 \%)$ before exposure to the secretion compared to $21.9 \%$ of control (no secretion) trials after exposure to the secretion. These results suggest that there is a generalization or carry-over effect due to experience with the secretion in the test situation. Two further experiments were run with a counterbalanced design to investigate this effect further, but too little sexual behavior was observed to obtain significant results (see general discussion).

The experimental males spent more time within 5 in. of the castrates when the vaginal secretion was present (Table 2, $\mathrm{t}=2.689, \mathrm{p}<.05$ ), and also sniffed more at the genital region of scented partners $(74.9 \mathrm{sec})$ than at the genital region of unscented partners $(41.2 \mathrm{sec}$, $t=3.137, p<.05)$ or at the genital region of their partners during habituation trials $(30.8 \mathrm{sec}, t=5.872$, $\mathrm{p}<.005$ ). During test trials, the difference in sniffing at the genital region was most obvious at the beginning of the encounter; if only the first $45 \mathrm{sec}$ of encounters were considered, the males sniffed $19.8 \mathrm{sec}$ with added secretion and $11.5 \mathrm{sec}$ without $(t=4.761, p<.01)$. Sniffing at the head and other body regions was not significantly different in any of the three conditions.

In addition to stimulating sexual behaviors, the vaginal secretion reduced the occurrence of two agonistic behaviors. There was less time spent in mutual agonistic postures (Table 2, $\mathrm{t}=4.343, \mathrm{p}<.01$ ), and five of the six males showed a lower frequency of flank marking in the presence of vaginal secretion (Table 2, $\mathrm{t}=1.817, \mathrm{p}<.2$; with nonparametric Walsh test, $\mathrm{p}<.06$, two tailed). During the habituation trials, much time was spent in mutual agonistic postures (mean, $63.7 \mathrm{sec}$ ), significantly greater than the time in mutual agonistic postures during test trials either with or without added vaginal secretion (Table 2; with secretion $t=4: 392, p<.01$; without secretion $t=3.497, p<.02$ ).

\section{GENERAL DISCUSSION}

The experiments demonstrated that vaginal secretion from an estrous female hamster was sufficient to elicit sexual behavior from sexually naive male hamsters towards normally inappropriate partners. In both experiments, all indices of sexual behavior (frequency of mount attempts, seconds engaged in mount attempts, and latency to mount) were significantly different in the presence of vaginal secretion, confirming results reported by Murphy (1973) with sexually experienced males and, as stimulus animals, anesthetized males or young males. Attempted mounting was not an invariant or automatic response to the presence of vaginal secretion, however, and during $36 \%-50 \%$ of the trials in which exogenous secretion was present, no sexual behavior was observed. Individual differences were also apparent in the frequency of sexual behavior and the degree to which it seemed to be under vaginal secretion control.

Males spent more time close to scented vs. unscented stimulus animals, and this confirms previous studies which demonstrated attraction to the vaginal secretion odor in two-bottle preference tests by both sexually experienced and sexually naive males (Johnston, 1970, 1972, 1974d; Murphy, 1973; Devor \& Murphy, 1973). Sexual attraction and mounting initiation functions are consistent with a third possible function, proper orientation of the male towards the female. It would be interesting to investigate the behavior of males toward females lacking the vaginal secretion. Such experiments would establish whether the presence of the secretion is necessary for elicitation of mounting and, if not, what deficits occur in its absence.

In addition to sexual functions, the vaginal secretion may reduce aggressive tendencies of males. The most direct indication of this occurred in Experiment II in which time spent in mutual agonistic postures was less when the secretion was present. Murphy (1973) also reported significantly less time spent in "attack" towards either anesthetized males or young active males when vaginal secretion was present. In both Experiments I and II above, vigorous fighting and chasing were relatively rare, and there were no significant differences between the two odor conditions. However, all of these 
measures are a result of the interaction between two animals. Stimulus animals often initiated tumbling or fighting when they were mounted-in Experiment I, $57.6 \%$ of all bouts of tumbling were preceded by mount attempts-and thus the time spent in agonistic behavior is not necessarily an accurate reflection of the aggressiveness of one member of a pair. Perhaps a better indication of aggressive motivation is flank-marking frequency (Johnston, 1970, 1974a, 1974c; Note 2 and Note 3) which was reduced in both experiments by the addition of vaginal secretion. Males are less aggressive towards females than towards other males (Johnston, 1970, 1974a; Payne \& Swanson, 1970), and it may be that the vaginal secretion is an important cause of this difference. Females produce some vaginal secretion throughout the estrous cycle (Orsini, 1961) and males sniff and lick the female's genital region, and occasionally attempt to mount, on all cycle days (Johnston, 1970, 1974a; Payne \& Swanson, 1970).

It is unlikely that the increase in sexual behavior observed in the presence of the vaginal secretion was due to its effects on the stimulus animals. The ovariectomized females rarely displayed any overt response to the secretion, and while the castrated males did occasionally sniff and lick the secretion, none of them engaged in mounting attempts or other sexual behaviors. Furthermore, in other experiments castrated males have shown greatly decreased attraction to the vaginal secretion in two-bottle preference tests (Gregory, Engel, \& Pfaff, 1975). The vaginal secretion has also elicited mounting of anesthetized males (Murphy, 1973) and anosmic males (Lisk, Zeiss, \& Ciaccio, 1972), conclusively demonstrating that olfactory sensitivity of stimulus animals is not necessary for the effect to be observed.

The mean frequency and duration of mounting in Experiment I was almost twice that observed in Experiment II for both stimulus and control conditions (see Tables 1 and 2). Such differences could be due either to behavioral differences of the stimulus animals (ovariectomized females vs. castrated males) or to differences in other sensory cues emanating from them. Since the time spent in agonistic behaviors was also slightly greater with ovariectomized females, it seems unlikely that these females were either more solicitous or more docile than the castrated males. It may be that the experimental males could still "identify" the sex of the stimulus animals by odor. One relevant comparison is that the seconds sniffing the genital region in Experiment I did not differ between the scented and unscented conditions, whereas in Experiment II with castrated males the genital region was sniffed significantly more when vaginal secretion was added. This suggests that the ovariectomized females were still producing some vaginal secretion throughout the experiment; if true, this would also explain the greater amount of sexual behavior observed in Experiment $I$ compared to Experiment II. This conclusion is supported by recently reported experiments in which vaginal secretion squeezed from ovariectomized females and placed on anesthetized males was sufficient to elicit sexual behavior from males (Darby, Devor, \& Chorover, 1974).

After completion of the second experiment, two further experiments were run in an attempt to investigate the effects of experience with the secretion and to verify the suitability of using castrated males as the stimulus animals for behavioral bioassay of vaginal secretion components. The experimental procedure was similar to Experiments I and II except for the sequence of testing: a series of control trials was followed by a series of vaginal secretion trials and then another series of control trials. In Experiment III, the castrated stimulus animals were quite young, all were beaten in fights with the experimental males, and they spent a large part of the encounter period fleeing from the experimental animals. Only one of six experimental males engaged in mounting attempts, which occurred only during vaginal secretion trials. There were significant uffects of the secretion on sniffing the genital region and time within 1 in., but only when comparing the first control series with the stimulus series. In Experiment IV, the castrated males were older and larger than the experimental males, and in all pairs the castrate was the dominant. The subordinate status of the experimental males inhibited approach and sexual behavior toward the castrates. Nonetheless, three experimental males did mount their partners, with means of $1.0,0.7$, and 3.5 mounts per trial in the presence of secretion and $0.0,0.0$, and 0.5 mounts per trial, respectively, without secretion. There were several other significant effects of the secretion which agreed with those in Experiments I and II: in the presence of the vaginal secretion, more time was spent within 1 in. and sniffing at the genital region of the partner, and less time was spent in mutual agonistic postures and at distances greater than $5 \mathrm{in}$. away. In general, however, most of the effects of the vaginal secretion seen in Experiments I and II were not significant in Experiments III and IV, indicating the importance of the social context. Thus, it is obvious that castrated males are not ideal stimulus animals for behavioral assay of vaginal secretion components. Anesthetized stimulus animals, whose features remain relatively constant from one trial to the next, would appear to be a better choice (Darby, Devor, \& Chorover, 1974; Murphy, 1973).

The golden hamster is the first mammalian species for which it has been demonstrated that sex pheromone effects of the signaling type are independent of adult sexual experience. The attraction of male rats to estrous female urine depends on prior sexual experience (Carr, Loeb, \& Dissinger, 1965; Lydell \& Doty, 1972), and apparently only experienced male rhesus monkeys have been used in testing responses to female vaginal 
pheromones (Micahel \& Keverne, 1968, 1970; Michael, Keverne, \& Bonsall, 1971). This independence from sexual experience suggests the existence of olfactory perceptual mechanisms specialized for detection and response to the vaginal secretion. However, several results suggest that vaginal secretion pheromones do not have an automatic "releasing" type of effect on a male's behavior. In the present experiments, there were considerable individual differences in the responsiveness to the secretion, and social context factors, such as relative dominance, greatly affected the behaviors elicited by the secretion. Furthermore, since sexual behaviors are rarely directed toward furry models scented with vaginal secretion (Darby, Devor, \& Chorover, 1974; Johnston, unpublished observations) but are common towards anesthetized males scented with vaginal secretion (Darby, Devor, \& Chorover, 1974; Murphy, 1973), some further cues from hamsters are necessary for vigorous responsiveness. The nature of these additional cues are unknown, but some are likely to be olfactory, and they might be involved in species recognition. Awake partners also engage in postures and vocalizations which may influence initiation of mounting (Floody, 1974). Thus, there are undoubtedly numerous cues whose effects summate to influence the sexual behavior of males, but it remains an open question whether or not the vaginal secretion is necessary for initiation of mounting.

\section{REFERENCE NOTES}

1. Johnston, R. E, Scent marking in female hamsters. Paper presented at Eastern Psychological Association meetings, Atlantic City, 1970.

2. Johnston, R. E. Influence of odours and oestrous cycle on scent marking by female hamsters (Mesocricetus auratus), 1974, unpublished manuscript.

3. Johnston, R. E. Effects of social encounters and oestrous cycle on scent marking female hamsters, (Mesocricetus auratus), 1974, unpublished manuscript.

\section{REFERENCES}

Brom, G., \& Schwartz, H. B. Acute changes in the estrous cycle following ovariectomy in the golden hamster. Neuroendocrinology, 1968, 3, 366-377.

Bronson, F. H. Pheromonal influences on mammalian reproduction, In: $M$. Diamond (Ed.), Reproduction and sexual behavior. Bloomington: Indiana University Press, 1968.

Carr, W. J., Loeb, L. S., \& Dissinger, M. L. Responses of rats to sex odors. Journal of Comparative and Phy siological Psycholosy, 1965, 62, 336-338.

Darby, E. M., Devor, M., \& Chorover, S. L. A presumptive sex pheromone in the hamster: Some behavioral effects. Journal of Comparative and Physiological Psychology, 1974, in press.

Devor, M., \& Murphy, M. R. Social agnosia produced by peripheral olfactory blockage in hamsters. American Zoologist, 1972, 12,653.

Devor, M., \& Murphy, M. R. The effect of peripheral olfactory blockade on the social behavior of the male golden hamster. Behavioral Biology, 1973, 9, 31-42.

Dieterlen, F. Das verhalten des syrischen goldhamsters, (Mesocricetus auratus Waterhouse). Zeitschrift fur Tierpsychologie, 1959, 16, 47-103.
Eisenberg, $J_{c}$ F., \& Kleiman, D. Olfactory communication in mammals. Annual Review of Ecology and Systematics, 1972, $3,1-31$.

Ewer, R. F. Ethology of mammals. New York: Plenum Press, 1968.

Floody, O. R. Ultrasonic communication and the hormonal modulation of aggressive behavior in the female hamster. Unpublished thesis, Rockefeller University, 1974.

Gregory, E., Engel, K., \& Pfaff, D. Male hamster preference of female hamster vaginal secretions: Studies of experimental and hormonal determinants. Journal of Comparative and Physiological Psychology, 1975, in press.

Johnson, R. P. Scent marking in mammals. Animal Behavior $1973,21,521-535$

Johnston, $\dot{R}$. E. Scent marking, olfactory communication and social behavior in the golden hamster, (Mesocricetus auratus). Unpublished doctoral dissertation, Rockefeller University, 1970. University Microfilms, 1970, No. 72-12, 666 .

Johnston, R. E. Sex pheromones of the golden hamster. American Zoologist, 1972, 12, 662 .

Johnston, R. E. Scent marking by male hamsters I. Effects of odors and social encounters. Zeitschrift für Tierpsychologie, 1974 , in press. (a)

Johnston, R. E. Scent marking in male hamsters II. The role of flank gland odor in the causation of marking. Zeitschrift für Tierpsychologie, 1974 , in press. (b)

Johnston, R, E. Scent marking by male hamsters III. Behavior in a semi-natural environment. Zeitschrift füx Tierpsychologie, 1974 , in press. (c)

Johnston, R. E Sexual attraction function of golden hamster vaginal secretion. Behavioral Biology, 1974, 12, 111-117. (d)

Lisk, R. D., Zeiss, J , \& Ciaccio, L. A The influence of olfaction on sexual behavior in the male golden hamster. (Mesocricetus auratus). Journal of Experimental Zoology, 1972, 181, 69-78.

Lydell, K.. \& Doty, R. L. Male rat odor preferences for female urine as a function of sexual experience, urine age, and urine source. Hormones and Behavior, 1972, 3, 205-212.

Michael, R. P., \& Keverne, E. B. Pheromones in the communication of sexual status in primates. Nature, 1968 , $218,746-749$.

Michael, R P.. \& Keverne, E. B. Primate sex pheromones of vaginal origin. Nature, $1970,225,84-85$.

Michael, R. P., Keverne, E. B., \& Bonsall, R. W. Pheromones: Isolation of male sex attractants from a female primate. Science, 1971, 964-966.

Murphy, $M$. $\widehat{R}$. Effects of female hamster vaginal dischange on the behavior of male hamsters. Behavioral Biology, 1973, 9 , 367-375.

Murphy, M. R., \& Schneider, G. E. Olfactory bulb removal eliminates mating behavior in the male golden hamster. Science, 1970, 167, 302-304.

Mykytowycz, $R$. The role of skin glands in mammalian communication. In: J. W. Johnston, D. G. Moulton, and A. Turk (Eds.), Advances in chemoreception, Communication by chemical signals (Vol. 1). New York: Appleton-Century-Crofts, 1970.

Orsini, M. W. The external vaginal phenomena characterizing the stages of estrous cycle, pregnancy, pseudopregnancy. lactation, and the anestrous hamster, (Mesocricetus auratus Waterhouse). Proceeding of Animal Care Panel, 1961, 11, 193-206.

Payne, A. P., \& Swanson, H. H. Agonistic behavior between pairs of hamsters of the same and opposite sex in a neutral observation area. Behaviour, 1970, 36, 269-269.

Payne, A. P., \& Swanson, H. H. The effect of sex hormones on the agonistic behavior of the male golden hamster, (Mesocricetus auratus Waterhouse). Physiology and Behavior, $1972,8,687-691$.

Ralls, $K$. Mammalian scent marking. Science, 1971, 171, $443-449$.

Schultz, E. F., \& Tapp, J. T. Olfactory control of behavior in rodents. Psychological Bulletin, 1973, 79, 21-44.

Whitten, $W$. $K$. Pheromones and mammalian reproduction. Advances in Reproductive Physiology, 1966, 1, 155-177.

(Received for publication August 6, 1974; revision accepted December 26,1974 .) 